\title{
The Effect of Prone Position on the Integrated Pulmonary Index (IPI) Score in Lumbar Disc Surgeries Performed with Spinal Anesthesia
}

\author{
- Sule Batcik, ๑ Osman Ersegun Batcik* \\ Recep Tayyip Erdogan University Faculty of Medicine, Department of Anesthesia and Reanimation, Rize, Turkey \\ ${ }^{*}$ Recep Tayyip Erdogan University Faculty of Medicine, Department of Neurosurgery, Rize, Turkey
}

\section{Abstract}

\begin{abstract}
Aim: It is a known fact that the prone position has curative effects on respiratory parameters. To evaluate the effect of prone position on respiratory status in lumbar discectomy operations with spinal anesthesia using integrated pulmonary index (IPI), which is a novel tool that incorporates different respiratory parameters.
\end{abstract}

Methods: A total of 40 patients were enrolled in this prospective, observational study between December 2020 and February 2021. The IPI parameters included end-tidal carbon dioxide, respiratory rate, pulse rate and oxygen saturation recorded at the time of admission to the operating room, at ten minutes after spinal anesthesia administration, at ten minutes following prone positioning and ten minutes after the end of the operation.

Results: The mean end-tidal carbon dioxide value significantly increased after prone positioning and at the end of the operation. The mean oxygen saturation similarly increased at the end of the operation. There was a moderately significant correlation between the mean IPI scores after prone positioning and ten minutes after the administration of spinal anesthesia.

Conclusion: Prone position did not show any negative effect on respiratory mechanics as obtained from IPI, while it increased oxygenation. IPI may be a valuable tool in clinical practice to monitor respiratory mechanics in the prone position in patients undergoing lumbar disc surgeries.

Keywords: Prone position, integrated pulmonary index, respiratory mechanics, anesthesia, spinal, diskectomy

\section{Introduction}

Lumbar disc herniation (LDH) is a localized displacement of intervertebral disc tissue beyond its physical margins, causing lower back pain, radicular pain, numbness and motor weakness. The incidence of LDH is between 5 and 20 per 1,000 adults with a male/female ratio of 2:1 (1). Lumbar discectomy, one of the most common treatment methods of $L D H$, is the most frequently performed spinal surgery operation by neurosurgeons (2).

Spinal anesthesia provides a safe and highly satisfying alternative to general anesthesia, especially or patients undergoing limited lumbar surgeries (3). The advantages of spinal anesthesia over general anesthesia in lumbar disc surgery include decreased use of antiemetics and analgesics, lower rates of hemodynamic and respiratory complications, shorter length of stay in hospital and reduced costs $(4,5)$. In addition, there are studies showing shorter operational times with spinal anesthesia (6).

The prone position is used during anesthesia to provide operative access in a wide variety of surgical operations, especially spinal surgeries. However, intraoperative complications such as accidental extubation and postoperative complications such as airway edema have been associated with prone position (7). In addition, since the abdomen and chest are restricted during the prone position, respiratory compliance decreases (8). Thus, placing an anesthetized patient into the prone position during spinal surgeries increases the risk of improper ventilation, making continuous monitoring of the respiratory status mandatory (9). Nevertheless, currently very little is known about the effects of prone position on respiratory mechanisms.

Address for Correspondence: Osman Ersegun Batcik, Recep Tayyip Erdogan University Faculty of Medicine, Department of Neurosurgery, Rize, Turkey 
The integrated pulmonary Index (IPI) incorporates four real-time respiratory measurements [end-tidal $\mathrm{CO}_{2}$, respiratory rate, pulse rate and peripheral oxygen saturation $\left(\mathrm{SpO}_{2}\right)$ ] into a single value between 1 and 10 , which represents the respiratory status of the patients (10). There is no study in the literature investigating the effect of prone position on respiratory status using the IPI. Therefore in this study, we aimed to evaluate the effect of prone position on respiratory status in diskectomy operations with spinal anesthesia using the IPI.

\section{Methods}

Before the beginning of the study, ethics approval was received from the Recep Tayyip Erdogan University, Noninterventional Clinical Research Ethics Committee with the 2020/214 numbered decision. All patients were informed about the objectives of the study and gave written consent. The study was conducted in accordance with the Declaration of Helsinki.

This prospective, observational, cross-sectional study included patients aged between 18-65 years, classified as American Society of Anesthesiologists (ASA) 1-2 according to the ASA, and scheduled for $\mathrm{L}_{4^{-}{ }^{\prime}}, \mathrm{L}_{5}-\mathrm{S}_{1}$ lumbar discectomy operation under spinal anesthesia between December 2020 and February 2021.

A total of 45 patients were included in the study. Two patients were excluded from the study, because spinal anesthesia was contraindicated, one patient because an adequate blockage could not be achieved and two patients due to missing data. Finally, the study was completed with 40 patients.

Patients with a basal mean arterial pressure (MAP) $<65 \mathrm{mmHg}$, a room air $\mathrm{SPO}_{2}<92$, and a heart rate (HR) out of the range of $45-120 \mathrm{bpm}$, those with a body mass index $(\mathrm{BMI})>30 \mathrm{~m}^{2} / \mathrm{kg}$, patients with previously defined respiratory problems, chest and spinal deformity, patients with insufficient blockage and those who needed additional analgesics and sedatives during the procedure were excluded from the study.

After taken to the operating room, all patients were followed-up with routine monitorization including electrocardiogram, noninvasive arterial blood pressure and IPI (Capnostream 20 Oridion Medical 1987 Ltd., Jerusalem, Israel). This software provides a single index between 1-10 based on 4 physiological parameters including end-tidal carbon dioxide pressure $\left(\mathrm{EtCO}_{2}\right)$, respiratory rate (RR), $\mathrm{SpO}_{2}$ and $\mathrm{HR}$ (Table 1).

Ringer lactate solution was initiated at $\mathrm{mL} / \mathrm{kg} / \mathrm{h}$ in patients with intravenous (i.v.) access provided. The patients were sedated with i.v. midazolam $(0.02 \mathrm{mg} /$ $\mathrm{kg}$ ) received $\mathrm{O}_{2}$ support at $2 \mathrm{~L} / \mathrm{min}$ with IPI monitor nasal cannula throughout the operational procedure. For spinal

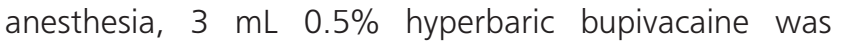

\begin{tabular}{|l|l|}
\hline \multicolumn{2}{|l|}{ Table 1. Integrated pulmonary Index scoring } \\
\hline $\begin{array}{l}\text { Integrated } \\
\text { pulmonary } \\
\text { Index }\end{array}$ & Patient status \\
\hline 10 & Normal \\
\hline $8-9$ & Within normal range \\
\hline 7 & Close to normal range - requires attention \\
\hline $5-6$ & Requires attention and may require intervention \\
\hline $3-4$ & Requires intervention \\
\hline $1-2$ & Requires immediate intervention \\
\hline
\end{tabular}

administered with a $25 \mathrm{G}$ spinal needle from the $L_{3-4}$ or $\mathrm{L}_{4.5}$ intervertebral space. The patients were kept waiting for ten minutes and given a prone position after the adequate block was evaluated with the pin-prick test and Bromage score. $10 \mathrm{mg}$ i.v. ephedrine was administered in the patients with a MAP that dropped more than $30 \%$ of the baseline value, and $0.5 \mathrm{mg}$ i.v. atropine in those with an $\mathrm{HR} \leq 45 \mathrm{bpm}$ after spinal anesthesia.

Patients' demographic (age, gender, BMI, ASA) and operative data were recorded and analyzed. Monitored MAP, EtCO $2_{2} R R, \mathrm{SpO}_{2}, \mathrm{HR}$ and IPI values were recorded at the time of admission to the operating room (TO), at ten minutes after spinal anesthesia administration (TSPI), at ten minutes following prone positioning (TPR) and ten minutes after the end of the operation in the supine position (TSPII).

\section{Statistical Analysis}

For the statistical analysis of the data obtained in this study, NCSS (Number Cruncher Statistical System) 2007 (Kaysville, Utah, USA) software was utilized. Descriptive statistical methods (mean, standard deviation, frequency, percentage, minimum, maximum) were used in the expression of the variables and the distribution was analyzed with the Shapiro-Wilk test. The comparison of non-normally distributed variables between two groups was made using the Mann-Whitney $U$ test. Whereas, Friedman test was used for comparisons of quantitative data for three or more non-normally distributed periods and the Wilcoxon test for comparison of the quantitative data between non-normally distributed two periods. The correlations within the variables were analyzed with Spearman's correlation analysis. $\quad P<0.05$ values were considered statistically significant.

\section{Results}

A total of 40 patients, including $22(55.0 \%)$ male and $18(45.0 \%)$ female, were included in this prospective observational study. The mean age of the patients was found as $48.03 \pm 12.9$ (range: $21-65$ ) years. Physical status of the patients at the time of admission was found as ASA1 in 17 (42.5\%) patients and ASA2 in 23 (57.5\%) patients. 


\section{Table 2. Demographic features of the patients}

\begin{tabular}{|c|c|c|}
\hline Age (Years), Mean \pm SD & - & $48.02 \pm 12.9$ \\
\hline BMI $\left(\mathrm{Kg} / \mathrm{m}^{2}\right)$, Mean \pm SD & - & $26.02 \pm 2.73$ \\
\hline \multicolumn{3}{|l|}{ Gender, n (\%) } \\
\hline Male & $22(55)$ & - \\
\hline Female & $18(45)$ & - \\
\hline \multicolumn{3}{|l|}{ ASA Status, n (\%) } \\
\hline ASA I & $14(42.5)$ & - \\
\hline ASA II & $23(57.5)$ & - \\
\hline \multicolumn{3}{|c|}{$\begin{array}{l}\text { SD: Standard deviation, ASA: American Society of Anesthesiologists, BMI: Body } \\
\text { mass index }\end{array}$} \\
\hline
\end{tabular}

The mean BMI was calculated as $26.02 \pm 2.73$ (range: $21.04-29.94) \mathrm{kg} / \mathrm{m}^{2}$. Demographic features of the patients are given in Table 2 . The mean sensory level was as 8.95 \pm 1.01 (range: 8-10) and the mean Bromage value was $2.73 \pm 0.45(2-3)$. The mean operational time was measured as $55.50 \pm 13.89$ (38-90) minutes.

When monitoring values of the patients were evaluated; $\mathrm{ETCO}_{2}$ and $\mathrm{SpO}_{2}$ values showed statistical significance according to the time points. Accordingly, the mean $\mathrm{ETCO}_{2}$ was significantly lower at TO compared to TPR and TSPII (POSTOP) values ( $p=0.001, p<0.01$; respectively). Similarly, the mean $\mathrm{ETCO}_{2}$ value was statistically significantly lower at TSPI compared to TPR and TSPII (POSTOP) values $\left(p=0.001, p<0.01\right.$; respectively). The mean $\mathrm{SpO}_{2}$ value was statistically significantly lower at TO and TSPI compared to TSPII (POSTOP) $(p=0.001, p<0.01$; respectively). No statistically significant difference was found between $H R, M A P, R R$ and IPI values according to the time points ( $p>0.05$ ) (Table 3).

Operative data included in the study were further compared between genders based on the time points. Accordingly, there was no statistically significant difference between the male and female patients in terms of the mean $\mathrm{HR}, \mathrm{MAP}, \mathrm{ETCO}_{2}, \mathrm{SpO}_{2}$ and IPI values at all time points (for all $p>0.05$ ). The mean RR value was significantly higher at TSPI in the female patients compared to the male patients $(p=0.02)$.

The correlations between the variables at different time points were evaluated with the Spearman's correlation analysis. Accordingly, there was a statistically significant difference between the mean HR value at TPR and the mean HR values at TO, TSPI and TSPII time points (for all $p<0.001)$. Similarly, significant correlations were found between the mean MAP and $\mathrm{ETCO}_{2}$ values at TPR and the mean $\mathrm{ETCO}_{2}$ values measured at other time points. A positive correlation was found between the mean RR values at $T P R$ and the mean RR values measured at TO and TSPI time points. The mean IPI value measured at TPR was positively correlated with the mean values measured at TSPI time point. Table 4 shows the correlation between the monitored values measured at ten minutes after prone positioning and the other time points.

\section{Discussion}

In the present study, we investigated the effects of the prone position on respiratory mechanics using the IPI scoring. Risks and benefits of the prone position during anesthesia in several surgeries have been controversial in the literature. Some studies have emphasized the increased oxygenation with prone position, while the others have underlined compromised pulmonary compliance $(11,12)$.

In a study by Palmon et al. (13) it was reported that the prone position increases the risk of improper ventilation during spine surgery. On the contrary, Miller reported that the lungs expanded better and oxygenation improved in patients under anesthesia in the prone position (14). The improvement of oxygenation with the prone position has been attributed to a reduction in intrapulmonary shunt that results in better ventilation (15). Furthermore, in this position, movement of the chest wall significantly increases, contributing to improved oxygenation. On the other hand, other beneficial hemodynamic effects with the prone position have been reported including increased exhalation volume, better blood circulation in the lungs and transformation of the effective area of the lungs (16). In a study by Black and Hawks, (17) $\mathrm{SPO}_{2}$ was significantly increased in $75 \%$ of the patients 30 minutes after prone positioning. Similarly, in a study by Yazdannik et al. (18) $\mathrm{SpO}_{2}$ value was significantly increased 30 minutes after prone positioning of the patients. In the present study, the mean $\mathrm{SPO}_{2}$ value was significantly higher at the end of the operation compared to the baseline value, showing a gradual improvement in oxygenation.

In an animal study comparing hemodynamic parameters between various positions during surgery, no difference was found between the positions in terms of the MAP (19). Again in a study by Cheng et al. (20) no significant difference was found between the MAP values during and at the end of the operation in the prone position. In our study, we could not find a significant difference between the mean MAP values at different time points.

In a study by Yadav et al. (21) with patients undergoing cervical spine surgery in supine and prone positions, no significant change was found in $\mathrm{ETCO}_{2}$ values with the prone position. In the present study, the mean $\mathrm{ETCO}_{2}$ value significantly increased after prone positioning compared to the baseline value. In a study by Ariagno et al. (22) less variability was reported in HR with the prone position. Studies in the literature reported no significant differences in RR with the prone position $(23,24)$. Similarly in our study, among the IPI parameters HR and RR values did not show significant variability with the prone position.

However, all the above-mentioned studies have been conducted in different patient populations undergoing different surgical operations in the prone position. Since 


\begin{tabular}{|l|l|l|l|l|l|l|}
\hline \multicolumn{2}{|l}{ Table 3. Monitoring values according to the time points } & T0 & TSPI & TPR & TSPII & (POSTOP) \\
\hline & & & & & \\
\hline HR & Mean \pm SD & $76.23 \pm 9.04$ & $73.8 \pm 10.13$ & $74.55 \pm 10.31$ & $76.9 \pm 10.22$ & 0.057 \\
\hline MAP & Mean \pm SD & $98.83 \pm 12.61$ & $94.75 \pm 11.82$ & $95.05 \pm 11.87$ & $98.63 \pm 11.15$ & 0.355 \\
\hline RR & Mean \pm SD & $16.88 \pm 3.86$ & $18.18 \pm 4.55$ & $16.65 \pm 3.1$ & $16.85 \pm 3.01$ & 0.165 \\
\hline ETCO & Mean \pm SD & $35.18 \pm 4.33$ & $34.53 \pm 4.62$ & $36.75 \pm 3.39$ & $36.73 \pm 3.8$ & $\mathbf{0 . 0 0 1 * *}$ \\
\hline SpO & Mean \pm SD & $97.2 \pm 2.37$ & $97.6 \pm 2.12$ & $97.28 \pm 6.39$ & $98.6 \pm 1.46$ & $\mathbf{0 . 0 0 1 * *}$ \\
\hline IPI & Mean \pm SD & $9.65 \pm 0.7$ & $9.33 \pm 1.12$ & $9.78 \pm 0.42$ & $9.78 \pm 0.58$ & 0.11 \\
\hline $\begin{array}{l}\text { Friedman test ** }<<0.01: \text { Statistical significance } \\
\text { HR: Heart rate, MAP: Mean arterial pressure, RR: Respiratory rate, ETCO }: \text { End-tidal carbon dioxide, SpO }: \text { Oxygen saturation, SD: Standart deviation }\end{array}$ \\
\hline
\end{tabular}

\begin{tabular}{|c|c|c|c|c|c|c|}
\hline \multirow[t]{2}{*}{ TPR } & \multicolumn{2}{|l|}{ TO } & \multicolumn{2}{|l|}{ TSPI } & \multicolumn{2}{|c|}{$\begin{array}{l}\text { TSPII } \\
\text { (POSTOP) }\end{array}$} \\
\hline & $r$ & $\mathbf{p}$ & $r$ & $p$ & $r$ & $p$ \\
\hline HR & 0.608 & $<0.001$ & 0.701 & $<0.001$ & 0.65 & $<0.001$ \\
\hline MAP & 0.544 & $<0.001$ & 0.708 & $<0.001$ & 0.532 & $<0.001$ \\
\hline $\mathbf{R R}$ & 0.531 & $<0.001$ & 0.317 & $<0.001$ & - & - \\
\hline $\mathrm{ETCO}_{2}$ & 0.619 & $<0.001$ & 0.672 & $<0.001$ & 0.534 & $<0.001$ \\
\hline $\mathrm{SpO}_{2}$ & - & - & 0.433 & $<0.001$ & 0.673 & $<0.001$ \\
\hline IPI & - & - & 0.467 & $<0.001$ & - & - \\
\hline
\end{tabular}

there is no study in the literature to evaluate the effects of the prone position on respiratory mechanics, we could not exactly compare our results with the other studies.

IPI is a decision-making algorithm that incorporates four respiratory parameters including $\mathrm{ETCO}_{2}, \mathrm{RR}$, pulse rate and $\mathrm{SpO}_{2}$ into a single value between 1 and 10 to indicate the respiratory status of patients (25). It combines ventilation monitoring and oxygenation monitoring and is measured by capnography. IPI is used by clinicians to evaluate the need for additional intervention. IPI score has been investigated in limited studies in the literature to evaluate respiratory mechanics. In a study by Mermer et al. (26) with geriatric patients undergoing spinal anesthesia, IPI scores were found to be in the normal range both in unilateral and bilateral spinal anesthesia. The authors reported that the IPI score may be valuable in early identification of respiratory failure. However, there was no study in the literature to investigate the effects of prone position on the IPI. In our study, there were no statistically significant changes in the mean IPI scores at all time points in the patients undergoing lumbar discectomy. On the other hand, there was a moderately significant correlation between the mean IPI scores after prone positioning and ten minutes after the administration of spinal anesthesia.

IPI score may be a useful monitoring tool to use in the operating room in the evaluation of respiratory status and to take necessary action timely. But more evidence is needed to routinely introduce this tool in anesthesia practice.

\section{Study Limitations}

This study has several limitations. First, the study included a relatively small number of patients treated in a single center. Second, IPI parameters could be compared with another group of patients in various variants of the prone position or with standard monitoring. However, the prospective design of the study is our strength. In addition, this study is the first in the literature to investigate the effects of the prone position on the IPI. Studies on IPI monitoring during anesthesia are very limited. Further studies are needed on this issue to confirm utility of the IPI index in monitoring during lumbar disc surgeries.

\section{Conclusions}

The results of this study indicate that the prone position did not show any negative effect on respiratory mechanics as obtained from IPI, while it increased oxygenation. IPI may be a valuable tool in clinical practice to monitor respiratory mechanics in the prone position in patients undergoing lumbar disc surgeries. It is an easy to handle tool showing many respiratory parameters together to timely alert anesthetists when necessary.

\section{Authorship Contributions}

Concept: S.B., Design: S.B., O.E.B., Data Collection or Processing: O.E.B., Analysis or Interpretation: S.B., Literature Search: S.B., O.E.B., Writing: S.B., O.E.B., 
Conflict of Interest: No conflict of interest was declared by the authors.

Financial Disclosure: The authors declared that this study received no financial support.

\section{References}

1. Al Qaraghli MI, De Jesus O. Lumbar Disc Herniation. In: StatPearls. Treasure Island (FL): StatPearls Publishing; April 2, 2021.

2. Hareni $N$, Strömqvist $F$, Strömqvist $B$, Sigmundsson FG, Rosengren BE, Karlsson MK. Back pain is also improved by lumbar disc herniation surgery. Acta Orthop 2021;92:4-8.

3. Sung TY, Jee YS, You HJ, Cho CK. Comparison of the effect of general and spinal anesthesia for elective cesarean section on maternal and fetal outcomes: a retrospective cohort study. Anesth Pain Med (Seoul) 2021;16:49-55.

4. Walcott BP, Khanna A, Yanamadala V, Coumans JV, Peterfreund RA. Cost analysis of spinal and general anesthesia for the surgical treatment of lumbar spondylosis. J Clin Neurosci 2015;22:539-43.

5. De Cassai A, Geraldini F, Boscolo A, et al. General Anesthesia Compared to Spinal Anesthesia for Patients Undergoing Lumbar Vertebral Surgery: A Meta-Analysis of Randomized Controlled Trials. J Clin Med 2020;10:102.

6. Pierce JT, Kositratna G, Attiah MA, et al. Efficiency of spinal anesthesia versus general anesthesia for lumbar spinal surgery: a retrospective analysis of 544 patients. Local Reg Anesth 2017;10:91-8.

7. Chui J, Craen RA. An update on the prone position: Continuing Professional Development. Can J Anaesth 2016;63:737-67.

8. Stone JG, Khambatta HJ. Pulmonary shunts in the prone position. Anaesthesia 1978;33:512-7.

9. Manna EM, Ibraheim OA, Samarkandi AH, Alotaibi WM, Elwatidy SM. The effect of prone position on respiratory mechanics during spinal surgery. Middle East J Anaesthesiol 2005; 18:623-30.

10. Turan G, Kuplay Y, Karip C, Koksal C, Akın C, Akgun N. Integrated Pulmonary Index: A New Strategy for Respiratory Patients Evaluation. Int J Anesthetic Anesthesiol 2016;3:042.

11. Taccone $P$, Pesenti $A$, Latini $R$, et al. Prone positioning in patients with moderate and severe acute respiratory distress syndrome: a randomized controlled trial. JAMA 2009;302:1977-84.

12. Pelosi P, Croci M, Calappi E, et al. Prone positioning improves pulmonary function in obese patients during general anesthesia. Anesth Analg 1996;83:578-83.

13. Palmon SC, Kirsch JR, Depper JA, Toung TJ. The effect of the prone position on pulmonary mechanics is frame-dependent. Anesth Analg 1998;87:1175-80.
14. Gropper M, Eriksson L, Fleisher L, Wiener-Kronish JP, Cohen N, Leslie K. Elsevier Health Sciences; 2014. Miller's Anesthesia.

15. Tawhai $\mathrm{MH}$, Nash MP, Lin $\mathrm{CL}$, Hoffman EA. Supine and prone differences in regional lung density and pleural pressure gradients in the human lung with constant shape. J Appl Physiol (1985) 2009;107:912-20.

16. Jozwiak M, Teboul JL, Anguel N, et al. Beneficial hemodynamic effects of prone positioning in patients with acute respiratory distress syndrome. Am J Respir Crit Care Med 2013;188:142833.

17. Black JM, Hawks JH. Saunders/Elsevier; 2009. Medicalsurgical nursing: Clinical Management for Positive Outcomes, 8 e without $C D$ A st edition.

18. Yazdannik A, Gholami F, Zerraatkari K, Saghaei M. Effect of prone position on cardiac and pulmonary indices in patients under mechanical ventilation. IJNR 2006;1:15-21.

19. Hwang $\mathrm{JH}$, Kwon $Y S$, Kang EH, et al. Prone positioning improves oxygenation without adverse hemodynamic effects during partial liquid ventilation in a canine model of acute lung injury. Korean J Intern Med 2004;19:237-42.

20. Cheng MA, Todorov A, Tempelhoff R, McHugh T, Crowder $\mathrm{CM}$, Lauryssen $\mathrm{C}$. The effect of prone positioning on intraocular pressure in anesthetized patients. Anesthesiology 2001;95:1351-5.

21. Yadav M, Reddy EP, Sharma A, Kulkarni DK, Gopinath R. The Effect of Position on $\mathrm{PaCO} 2$ and PETCO2 in Patients Undergoing Cervical Spine Surgery in Supine and Prone Position. J Neurosurg Anesthesiol 2017;29:298-303.

22. Ariagno RL, van Liempt S, Mirmiran M. Fewer spontaneous arousals during prone sleep in preterm infants at 1 and 3 months corrected age. J Perinatol 2006;26:306-12.

23. Antunes LC, Rugolo LM, Crocci AJ. Efeito da posição do prematuro no desmame da ventilação mecânica [Effect of preterm infant position on weaning from mechanical ventilation]. J Pediatr (Rio J) 2003;79:239-44.

24. Levy J, Habib RH, Liptsen E, et al. Prone versus supine positioning in the well preterm infant: effects on work of breathing and breathing patterns. Pediatr Pulmonol 2006;41:754-8.

25. Kumar V, Taft A, Johnson S, Herrington R, Castresana M. Integrated Pulmonary Index for Successful Weaning Obese Patients After Cardiac Bypass Surgery. Crit Care Med 2013;41pA90.

26. Mermer D, Turan G, Koksal C, Tas B, Karadogan F, Akgun $\mathrm{N}$. Correlation of integrated pulmonary index with clinical observation in unilateral and bilateral spinal anaesthesia in geriatric patients. Int J Res Med Sci 2016;4:4438-43. 